\title{
Altered hemodynamics in bicuspid aortic valve disease: Leaning more toward nurture!
}

\author{
M. Sertaç Çiçek, MD, FACC
}

\author{
From the Section of Cardiovascular Surgery, Anadolu Medical Center, Kocaeli, Turkey. \\ Disclosures: Author has nothing to disclose with regard to commercial support. \\ Received for publication Jan 6, 2017; accepted for publication Jan 12, 2017; available ahead of print Feb 14, 2017. \\ Address for reprints: M. Sertaç Çiçek, MD, FACC, Section of Cardiovascular Surgery, Anadolu Medical Center, \\ Cumhuriyet Mahallesi 2255 Sokak No: 3 Gebze, 41400 Kocaeli, Turkey (E-mail: scicek@mac.com). \\ J Thorac Cardiovasc Surg 2017;153:S63-4 \\ $0022-5223 / \$ 36.00$ \\ Copyright (c) 2017 by The American Association for Thoracic Surgery \\ http://dx.doi.org/10.1016/j.jtcvs.2017.01.016
}

Bicuspid aortic valve (BAV) is classified as the most frequently encountered congenital cardiac defect, with a prevalence between $1 \%$ and $2 \%$. These valves tend to degenerate, resulting in significant aortic stenosis and regurgitation. More importantly, BAV is associated with aortopathy that affects the aortic root, as well as the ascending aorta and aortic arch, as all tissues originate from the neural crest. Aortic dissection and rupture are the most serious complications, and notably BAV has been recognized as a risk factor for acute aortic dissection. ${ }^{1}$ The causes of thoracic aortic dilation in BAV have not been identified clearly. Two likely mechanisms are either hemodynamic flow disturbance, resulting in increased wall shear stress in the proximal aorta, and/or an unidentified genetic or developmental abnormality, resulting in congenital weakness of the aortic wall independent of the etiology of the bicuspid valve. $^{2}$

Clinical heterogeneity seen in BAV-associated aortopathy might be due to the severity of hemodynamic alteration and/or to individual genetic predisposition. The widely accepted theory that BAV disease is a genetic connective tissue abnormality has been challenged by many hemodynamic and anatomic observations. Echocardiographic studies have shown significantly greater peak aortic velocities at the anterolateral aspect of ascending aorta in patients with BAV compared with matched healthy objects and the location of elevated peak velocities correlating with the typical location of asymmetric aortic dilation. ${ }^{3,4}$ Furthermore, specific segments of dilated aorta vary with the type of aortic valve leaflet fusion, ${ }^{5}$ which is difficult to explain with a theory of genetic predisposition or connective tissue abnormality. Although still controversial, aortic valve replacement has been reported to slow the progression of aortic dilation. ${ }^{6}$ These findings raise the possibility that abnormal flow patterns play an essential role in development of aortic dilation in patients with BAV.

Since its introduction to clinical practice, phase contrast magnetic resonance imaging (MRI) has become a routine part of cardiac MRI for the assessment of the regional blood flow in the heart and great vessels. More recently,

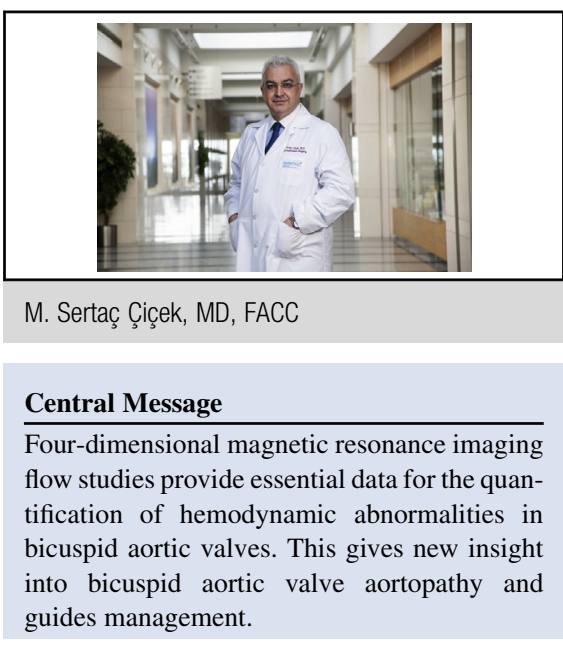

See Article page S52.

time-resolved phase contrast MRI with velocity encoding and 3-dimensional anatomic coverage (termed as 4-dimensional flow MRI) has been used to provide a comprehensive evaluation, which was unfeasible previously. ${ }^{7,8}$ Hope and colleagues ${ }^{9}$ showed markedly abnormal helical flow in the ascending aorta of patients with a BAV, including those without aneurysm or aortic stenosis. BAV demonstrates abnormal leaflet motion, including folding or wrinkling of the valve tissue and increased leaflet doming during the cardiac cycle that results in increased currents of turbulence even when the leaflets are not stenotic. Studies have demonstrated that these fluid dynamic stresses can promote local medial degeneration via matrix metalloproteinase-dependent pathways. ${ }^{2,10}$

In this issue of the Journal, Kimura and colleagues ${ }^{11}$ report the use of MRI-based computational fluid dynamics (CFD) to investigate wall shear stress distribution in 12 patients with a BAV. Abnormal aortic helical flow was seen in ascending aorta and transverse arch in all patients with BAV and in no patients (3 patients) with a tricuspid aortic valve. The patients with BAV were likely to have jet flow/wall impingement against the greater curvature of the proximal ascending aorta, resulting in remarkably increased wall shear stress around the impingement area. Although this is a small-size observational study with structural flaws, it will stimulate further research for understanding the pathophysiology of BAV disease. As the authors acknowledge, additional studies with larger and more clearly defined 
study groups and longitudinal follow-up are essential to link altered hemodynamics and the progression of aortic wall disease.

Aortic size still has been the primary parameter used to predict aortic aneurysm dissection/rupture potential ${ }^{12}$; however, this parameter fails to account dissection/rupture at smaller aortic sizes, or for those that reach extreme sizes without rupture. Currently, there are no truly reliable methods to evaluate the susceptibility of a particular aortic aneurysm to rupture. Maximal pressure and wall shear stress might lead to biomechanical wall failure and predict the site of rupture. Although CFD in the biomedical field has lagged behind because of the tremendous complexity of human body fluid behavior, creating a more-efficient CFD system and integrating it with 4D MRI flow analysis will provide essential data about aortic flow dynamics and biomechanics, leading to a more optimal risk assessment and treatment algorithms.

\section{References}

1. Michelena HI, Khanna AD, Mahoney D, Margaryan E, Topilsky Y, Suri R, et al Incidence of aortic complications in patients with bicuspid aortic valves. JAMA. 2011;306:1104-12.

2. Andreassi MG, Della Corte A. Genetics of bicuspid aortic valve aortopathy. Curr Opin Cardiol. 2016;31:585-92.
3. Nkomo VT, Enriquez-Sarano M, Ammash NM, Melton LJ III, Bailey KR, Desjardins V, et al. Bicuspid aortic valve associated with aortic dilatation: a community-based study. Arterioscler Thromb Vasc Biol. 2003;23:351-6.

4. Bauer M, Siniawski H, Pasic M, Schaumann B, Hetzer R. Different hemodynamic stress of the ascending aorta wall in patients with bicuspid and tricuspid aortic valve. J Card Surg. 2006;21:218-20.

5. Bauer M, Gliech V, Siniawski H, Hetzer R. Configuration of the ascending aorta in patients with bicuspid and tricuspid aortic valve disease undergoing aortic valve replacement with or without reduction aortoplasty. J Heart Valve Dis. 2006;15:594-600.

6. Regeer MV, Versteegh MIM, Klautz RJM, Schalij MJ, Bax JJ, Marsan NA, et al. Effect of aortic valve replacement on aortic root dilatation rate in patients with bicuspid and tricuspid aortic valves. Ann Thorac Surg. 2016;102:1981-7.

7. Kozerke S, Hasenkam JM, Pedersen EM, Boesiger P. Visualization of flow patterns distal to aortic valve prostheses in humans using a fast approach for cine 3D velocity mapping. J Magn Reson Imaging. 2001;13:690-8.

8. Frydrychowicz A, Harloff A, Jung B, Zaitsev M, Weigang E, Bley TA, et al. Time-resolved, 3-dimensional magnetic resonance flow analysis at $3 \mathrm{~T}$ : visualization of normal and pathological aortic vascular hemodynamics. $J$ Comput Assist Tomogr. 2007;31:9-15.

9. Hope MD, Hope TA, Meadows AK, Ordovas KG, Urbania TH, Alley MT, et al. Bicuspid aortic valve: four-dimensional MR evaluation of ascending aortic systolic flow patterns. Radiology. 2010;255:53-61.

10. Atkins SK, Sucosky P. Etiology of bicuspid aortic valve disease: focus on hemodynamics. World J Cardiol. 2014;6:1227-33.

11. Kimura N, Nakamura M, Komiya K, Nishi S, Yamaguchi A, Tanaka O, et al. Patient-specific assessment of hemodynamics by computational fluid dynamics in patients with bicuspid aortopathy. J Thorac Cardiovasc Surg. 2017;153: S52-62.

12. Della Corte A, Body SC, Booher A, Schaefers HJ, Milewski RK, Michelena HI, et al. Surgical treatment of bicuspid aortic valve disease: knowledge gaps and research perspectives. J Thorac Cardiovasc Surg. 2014;147:1749-57. 